\title{
LEITURAS DELEUZIANAS DE POETAS QUE SE AUTODENOMINAM MARGINAIS: CARTOGRAFANDO A PARTIR DA LITERATURA MENOR
}

\section{DELEUZEAN APPROACHES TO SELF-PROCLAIMED MARGINAL POETS: CARTOGRAPHY BASED ON THE MINOR LITERATURE}

Eliane Aparecida Bacocina ${ }^{1}$

\begin{abstract}
Resumo: O trabalho apresenta recortes de pesquisa de Doutorado, a partir de interlocução com um grupo que atua de maneira não formal com produção de poemas. O Sarau das Ostras constitui-se de cinco poetas e tem como inspiração a ostra, que diante dos obstáculos, resiste e produz a pérola, assim como o grupo, frente aos desafios cotidianos, produz poesia. A pesquisa intenciona trazer à discussão o papel e o lugar da escrita poética e o modo como dela o grupo se utiliza, reverberando em travessias de fronteiras do pensamento. A proposta de cartografar as práticas de invenção (escrita e produção poética) postas em ação por esta comunidade de escritores surgiu a partir dos estudos de Deleuze e Guattari (2003) e de Rolnik, (2011). O material de pesquisa é constituído de livros publicados pelos participantes, trechos de diálogos em entrevistas, observação de vídeos nos quais os poetas vivenciam experiências formativas diversas.
\end{abstract}

Palavras-chave: Literatura Menor; cartografia; devir.

\begin{abstract}
This paper presents a selection of discussions from a Doctorate research, which concerns the study of a group who acts, in a non-formal fashion, in the production of poems. "Sarau das Ostras" ("The Oysters' Sarau") is formed by five poets. It has, as an inspiration, the oyster-which, in the face of obstacles, resists and produces the pearl, just like the group produces poetry when faced with everyday challenges. The research aims at bringing into discussion the role and context of poetic writing, as well as the way it is used by the group, echoing in the crossing of thought's borders. The cartography of the invention practices (the poetic writing and production) put into action by this community of writers was theoretically inspired by the works of Deleuze and Guatarri (2003) and Rolnik (2011). The corpora include the participants' published books, excerpts from interview dialogues, and videos in which the poets have various formative experiences.
\end{abstract}

Keywords: Minor Literature; cartography; becoming.

\footnotetext{
${ }^{1}$ IFSP - Instituto Federal de Educação, Ciência e Tecnologia de São Paulo. E-mail: elianeab3@gmail.com.
} 
Periferia em versos falo de ti

Que choras, mas também ri

Que exala o cheiro da morte

E o doce olor do viver

Que inspira a alegria

Na molecada a correr

Que mostra a Dona Maria

Senhora grande guerreira

Com a sacola na mão

Catando as sobras da feira

Sob o sol dia após dia

De sua luta não se cansa

Nos olhos rasos d'água

Guarda a fé e a esperança

Periferia em versos falo de ti

Que guarda grandes guerreiros

Talentos a descobrir

Que tem no campo a pelada

Onde a criança sorri

Periferia por quem meu coração bate

Pois nasci em suas ruas

E jamais esqueço de ti.

"Periferia, em cada olhar uma dor

Em cada dor uma saudade."

A ti um verso. In: NP. Poesias de um mundo louco, 2011, p. 20.

O trabalho que se apresenta tem início com um convite - convite da autora ao leitor para aventurar-se e mergulhar na poética de escritas/falas/movimentos das pessoas e textos que se entrelaçam nessa trama. Muitos convites vieram antes - convite aceito pela autora / pesquisadora, a conhecer cada um dos participantes da pesquisa e a criar conexões a partir do entrelaçamento das trajetórias de cada um deles. Convite aceito pelos poetas-protagonistas da pesquisa que, por sua vez, aceitaram compartilhar suas histórias e criações. Criações que envolvem movimentos desterritorializados, políticos e coletivos.

O trabalho apresenta recortes de pesquisa de Doutorado realizada no Programa de Pós Graduação em Educação da UNESP / Rio Claro (BACOCINA, 2017), a partir de interlocução com poetas que se autodenominam marginais e constituem um grupo que atua de maneira não formal no litoral sul paulista com produção de poemas. O grupo, denominado Sarau das Ostras, constitui-se de cinco integrantes escritores de poemas e tem como inspiração a ostra, elemento comum no litoral, que diante dos obstáculos, resiste e produz a pérola, assim como o grupo que, frente aos desafios da vida cotidiana, produz poesia. Os poetas - Ludimar, Fernandes, Nego Panda, RO3P e Abel - se conheceram por meio de rodas poéticas, grupos de rap e eventos diversos e, a partir de processos diversos de identificação e afinidades, passaram a se encontrar e apresentar seus textos em saraus, além de realizar produções coletivas.

A pesquisa realizada teve por objetivo trazer à discussão o papel e o lugar da escrita poética, a partir do olhar para o modo como dela o grupo se utiliza, reverberando em travessias de fronteiras do pensamento e processos emancipatórios. A proposta de cartografar as práticas 
de invenção (escrita e produção poética) postas em ação por estes sujeitos nesta comunidade de escritores surgiu a partir dos estudos de Deleuze e Guattari, mais especificamente no livro Kafka: para uma literatura menor (2003) e de Rolnik, em Cartografia Sentimental (2011).

O material de pesquisa é constituído por leitura de livros publicados pelos poetas, trechos de diálogos em entrevistas abertas, às quais intitulou-se "Conversas poéticas", observação de vídeos nos quais os corpos dos poetas se apresentam, vivências formativas diversas e impressões da pesquisadora, que foram sendo compostas durante o período de estudos e da elaboração da tese. A própria composição do texto da tese revelou-se um processo de expansão de pensamento... Foi se produzindo uma escrita outra, que não se conteve aos limites da escrita acadêmica... A partir das pistas deixadas pela denominação de um estilo anunciado pelo grupo - marginal, permitiu-se seguir as margens. Para ondem levaram? Das margens da página, margens do rio, margens que se situavam nas periferias, margens do pensamento poético, a tese foi seguindo em direção a um mar de possibilidades... devires...

Foi possível identificar, nas produções do grupo alguns elementos que remetem a uma escrita que é desterritorializada, política e coletiva, conforme delineado por Deleuze e Guattari ao abordarem a literatura menor: a desterritorialização, as políticas presentes nas práticas e a visão coletiva presente nos processos de escrita dos poemas.

\section{Cartografia}

Sobre a cartografia, Rolnik descreve o cartógrafo como um antropófago: “O cartógrafo é um verdadeiro antropófago: vive de expropriar, se apropriar, devorar e desovar, transvalorado. Está sempre buscando elementos / alimentos para compor suas cartografias" (ROLNIK, 2011, p. 65).

Expropriar... apropriar... compor com elementos.

Como elementos / alimentos da pesquisa, o que tenho à minha frente?

Transcrições de falas, textos produzidos, reflexões, imagens, poemas, teorias diversas, acontecimentos inusitados... O que posso compor com eles?

Como construir uma pesquisa que, como a autora me desafia na leitura que faço, possibilite "mergulhar na geografia dos afetos e, ao mesmo tempo, inventar pontes para fazer sua travessia: pontes de linguagem" (p. 66)?

(...) mergulhar na geografia dos afetos e, ao mesmo tempo, inventar pontes para fazer sua travessia: pontes de linguagem. (...). Vê-se que a linguagem, para o cartógrafo, não é um veículo de mensagens-e-salvação. Ela é, em si mesma, criação de mundos. Tapete voador... (ROLNIK, 2011, p. 66).

Pontes móveis, que levam àquilo que afeta. Busco mais pistas de como fazer uma cartografia: "desenho que acompanha e se faz ao mesmo tempo que os movimentos de transformação da paisagem" (ROLNIK, 2011, p. 23).

Reporto-me ao modo como encontrei os poetas, não em momento em que buscava um objeto de pesquisa, mas a partir de encontros em sala de aula e locais que frequentei como professora de turmas de Pedagogia. Em meio a cenários que iam se desenhando e movimentando à minha frente, transformando relações professora-alunos em pontes de relações que desenvolviam afetos.

Em alguns momentos, lendo sobre cartografia, me vem à mente a construção de um mapa. No entanto, a própria autora a diferencia:

"A cartografia, diferentemente do mapa, é a inteligibilidade da paisagem em seus acidentes, suas mutações”. (ROLNIK, 2011, p. 62). 
Por entre mutações de paisagens, fui construindo, então, meu objeto de pesquisa.

Uma tarefa: cartografar as sensações presentes em falas de poetas e livros de poemas.

Os autores: poetas que escrevem sobre temas sociais, sujeitos-protagonistas da pesquisa.

O lugar: litoral sul paulista, em seus ambientes de praias, praças, livrarias, bibliotecas.

Objetivos: compor com os sentidos produzidos no cotidiano do processo de formação de escritores a partir de situações de interlocução com o grupo proposto e atividades artísticas, como forma de conhecer e valorizar os saberes trazidos pelos diferentes sujeitos que compõem e atuam nesse espaço.

Questão de pesquisa: De que forma as imagens poéticas, produzidas em forma de versos, oralizados e escritos por poetas que se dizem "marginais" permitem extravasar as margens do pensamento?

Qual o potencial de criação desse pensamento que se diz em linguagem poética?

\section{Práticas, (des)territorializadas, políticas, coletivas}

Aqui, relato meu encontro com Deleuze e Guattari (2003) - os autores, ao analisarem a escrita de Kafka, escrevem sobre o valor daquilo que chamam "literatura menor". Outra questão de pesquisa surge:

Que indícios valorativos podem ser captados na "literatura marginal periférica", como nomeada pelos poetas e a "literatura menor", como referida por Deleuze e Guattari?

$\mathrm{O}$ que, nos seus escritos, pode dar a ver uma "língua menor"?

Vamos ao que dizem Deleuze e Guattari:

"Uma literatura menor não pertence a uma língua menor, mas, antes, à língua que uma minoria constrói numa linguagem maior" (DELEUZE; GUATTARI. 2003, p. 38). Essa seria a primeira característica desse tipo de literatura. A impossibilidade de escrever de outra maneira, que tem uma inter-relação com o que chamam de desterritorialização.

O que vem a ser essa desterritorialização na / pela escrita poética desses autores?

A desterritorialização se mostra por meio de escritas que desvelam as próprias histórias de vida e saberes dos autores, considerando vivências em espaços abertos e periferias.

A segunda característica é que nela, tudo é político.

De que modo pode-se compreender que tudo o que fazem, como fazem, é político?

É possível enunciar que as produções do grupo expressam visões políticas, apresentadas a partir de temáticas da vida cotidiana de personagens que resistem a sistemas pré-definidos.

A terceira se relaciona ao fato de que tudo nela toma um valor coletivo.

E acrescentam:

É a literatura que se encontra carregada positivamente desse papel e dessa função de enunciação colectiva e mesmo revolucionária: a literatura é que produz uma solidariedade activa apesar do cepticismo; e se o escritor está à margem ou à distância da sua frágil comunidade, a situação coloca-o mais à medida de exprimir uma outra comunidade potencial, de forjar os meios de uma outra consciência e de uma outra sensibilidade. (DELEUZE; GUATTARI, 2003, p. 40).

A questão coletiva pode ser evidenciada em trechos de poemas que remetem a construções do grupo, por exemplo, no verso "O barato é loko", muitas vezes citado por eles em diferentes contextos.

Olhando para os escritos e falas do Sarau das Ostras (assim identificam a composição do grupo), como seria possível compor com esses elementos, apontados por Deleuze e Guattari? A produção de uma escrita que é singular, possui particularidades, mas que ao mesmo tempo é 
coletiva? O que evidencia uma voz que é a de quem escreve, mas que reflete a voz de uma comunidade que possui em comum revoltas, inquietações, sentimentos e que se sente representada naquilo que ouve e lê? E cria?

São perguntas que me passam, enquanto pesquisadora, mas que não consigo colocar em palavras, conceituar. Seria a linguagem poética capaz de explicar?

Talvez um caminho possível para traçar meu roteiro inicial de estudo seja sair em busca desses três movimentos:

- DESTERRITORIALIZAR-SE

- SER POLÍtico

- coletivo

Para o caminhar por entre esses movimentos, um aviso ao leitor: autores irão se misturar em alguns momentos, autores por vezes que seguem perspectivas diferentes entre si. Movimento de escrita-pensamento. Devir.

Não consigo, envolvida por esse espaço poético, visualizar nesse momento outro modo de fazer pesquisa. Pesquisa que não propõe se explicar por conceitos e definições.

Pesquisa movediça.

Pesquisa que se propõe a caminhar em direção a um fazer poético.

As pegadas seguem.... Para onde me levam?

\section{Poemas para declamar}

Destaca-se, para esse trabalho, de forma particular, a forma como alguns poemas produzidos pelo grupo parecem ser produzidos para declamar, a partir de movimentos da voz, do corpo e das mãos. São poemas que, ao serem lidos, precisam ser escutados em voz alta, visualizados em seus modos possíveis de performance. Os poetry slams apresentados pelo grupo revelam uma potência de possibilidade e de criação que não se explica, mas que precisa ser vivenciada por meio de processos de experimentação. Dois elementos, dentre tantos, despertaram minha atenção:

- O “não caber": Despertam a atenção os relatos de dois poetas do grupo, quando afirmam que aquilo que querem escrever, muitas vezes, não cabe nas margens da folha e é necessário criar estratégias de oralização, a fim de demonstrar, nos momentos de apresentação do grupo, trazer aos espectadores algumas sensações que possam remeter ao contexto de produção.

- Inusitado: Muitas vezes, a intenção do grupo é promover o inusitado, a partir das sensações que podem ser despertadas e dos "baratos" que podem ser proporcionados a cada apresentação.

\section{Poesia e vivências... escrita e invenção}

Até que ponto aquilo que se escreve está relacionado às vivências? O quanto o devirescrita traz de invenção?

Quando pergunto a RO3P, poeta e rapper, se em sua escrita tem algo de sua vivência, ele diz que:

Geralmente sim, eu por ser muito rueiro eu acabo vendo muita coisa na rua, muita coisa boa, muita coisa ruim e acabo conseguindo transformar essa agonia em música... e informações também, eu converso com muita gente, de repente a gente ta conversando aqui e se você comentar alguma coisa, um certo tema e me chamar a atenção, eu vou pesquisar e 
escrever sobre o tema, é uma mistura, assuntos de rua, vida pessoal, mas nunca ficção, sempre realidade mesmo.

Eliane: Tem algum exemplo?

Pelé: $O$ maior exemplo foi a minha música Milhares, foi o maior de tudo assim, porque eu peguei muita coisa que eu vivo, muita coisa que eu vivi e coloquei ela assim, escrevi, todas as músicas tem o pessoal, todas, mas a mais forte foi a Milhares. Tem no CD. A milhares, a mais pessoal de todas.

Ligo o CD em busca da música. O sonho dus guerreiros não morre. Faixa 7. A música começa assim:

Tô vivão, na caminhada áspera e crônica.

No ritmo frenético na areia de sodoma.

Viver, vida chorona não é se impor diante o tempo.

As visões é que te faz ser fortaleza em andamento.

Momentos eu, tive e você teve as vontades.

Ser notável só pra elas o destaque em vaidade.

Simplicidade não sei, se pá nem tanto assim.

Um degrau só de progresso é bastante pra se exibir,

Nas louca tentação urbana, entre justos e sacanas.

Pros ousados e pacatos seduções são levianas.

Provocante, tipo lá no éden como antes.

(Pelé RO3P. Milhares. In: Gotas de vinagre, p. 43 e RO3P. O sonho dus guerreiros não morre! Faixa 7, 2013).

Milhares. A mais pessoal de todas...

Sempre realidade...

Sim, muita realidade. Imagino a caminhada de RO3P. Caminhada áspera. Ritmo frenético. Seduções levianas.

Mas e as referências a Sodoma, ao Éden...?

Ficção?

Invenção?

Inacabamento?

Literatura?

Mas na resposta, ele é claro:

Eliane: E tem alguma que você inventou e não tem a ver com o seu mundo?

RO3P: Não, nenhuma, todas tem a ver...

E Nego Panda? Escreve por quê? Onde está a poesia? No poema... na vida...

Pergunto: E o que você coloca seu quando você escreve? Você coloca alguma coisa sua? Ou você inventa?

Nego Panda: É sociedade, é visão de mundo, como cita o Paulo Freire. É o mundo... Eu gosto muito de escrever sobre a sociedade, sobre as questões sociais. Acho que tudo, tudo o que ta aí é poesia. A gente só não descobriu, mas tudo é poesia, falta descobrir. Muita gente não descobriu ainda, mas tem poesia em tudo. Tem poesia em tudo. Tem poesia na criança que ta brincando na rua, na criança que ta empinando pipa, tem poesia na pessoa que ta tomando banho de mar, tem poesia no cara que acabou de ser atropelado, não é uma poesia alegre mas 
tem poesia e você vai fazer um verso crítico a respeito daquilo porque o cara foi atropelado porque o outro tava alcoolizado, então você vai acabar fazendo um texto sobre isso pra conscientizar as pessoas que não dirijam depois de beber.

Tem poesia em tudo.

O que diz Deleuze?

Do que viu e ouviu, o escritor regressa com os olhos vermelhos, com os tímpanos perfurados. Qual saúde bastaria para libertar a vida em toda parte onde esteja aprisionado pelo homem e no homem, pelos organismos e gêneros e no interior deles? A frágil saúde de Spinoza, enquanto dura, dá até o fim o testemunho de uma nova visão à passagem da qual ela se abre. (DELEUZE, 1997, p. 14).

Olhos... Tímpanos... O corpo do escritor.

E quando a escrita tem papel de resposta? Quantas vivências existem, anteriores à escrita do poema, para que o poeta tenha o objetivo de responder aquilo que ouviu e vivenciou?

Ludimar conta que, com alguns de seus poemas, teve sim a intenção de dar respostas a coisas que a incomodam.

Ludimar: Tanto que se eu tivesse a agilidade que eles têm, quando uma senhora num evento, que eu acabei de cantar o rap olhou pra amiga dela com olhar irônico pra amiga dela e perguntou: "A Ludimar cheirou ou bebeu?" Mas eu demorei pra fazer a resposta.

Eliane: Isso aconteceu mesmo então...

Fernandes: Aí é a história da resposta.

Ludimar: Quando acabei de cantar o rap, aî eu queria ter a agilidade que eles têm de fazer na hora. Aí na próxima reunião a pessoa estava lá. Não citei nome nada. "Cheirou ou bebeu?" Então ficou uma resposta que eu dei não só pra ela, mas pra burguesia. (trecho da transcrição do $1^{\circ}$ encontro das Conversas Poéticas, 08/06/2013).

Um dia fui cantar meu rap longe da periferia,

Fui cantar pra burguesia, mas eu me arrependi.

A burguesia é preconceituosa.

Não gosta da nossa prosa.

Quando terminei de cantar meu rap

A burguesia perguntava se eu cheirei ou se bebi.

Não, minha senhora burguesa,

você pode ter certeza, não cheiro nem bebo,

mas carrego dentro do peito

uma grande vontade de fazer tudo direito.

O nosso movimento conta com gente digna,

Trabalhadora e decente que sabe cuidar da mente

E quer melhorar o mundo.

Esse mundo tão desigual onde o bem sofre com o mal.

Onde o pobre favelado não passa de um coitado.

Não tem chance de vencer.

E quando vence é discriminado, rejeição pra todo lado.

Quem sabe um dia, toda essa burguesia entenda

$\mathrm{O}$ nosso recado queira nos conhecer melhor. 
Todos juntos na estrada. Esperança renovada.

Voltei pra periferia.

Lutarei para que, um dia, nossa voz seja ouvida.

Não mais sejamos vistos como vagabundos

E cheiradores, da sociedade infratores e sim como cidadãos.

Estou mais tranquilo agora depois desse desabafo.

A verdade eu não abafo. Faço uso da razão.

Sigo em paz o meu caminho. Na luta não estou sozinho.

Tá ligado, meu irmão?

(MOLINA, 2011, p. 36).

Fernandes, autor do livro Minhas pegadas na areia (FERNANDES OLIVEIRA, 2011), escrever poemas desde a adolescência e também tem história pra contar.

Fernandes: Sobre resposta. Muitos dos textos meus surgiram a partir de respostas, sejam amorosas, sejam de repúdio, ai eu falo "você falou isso pra mim. Então ouça o que eu tenho pra te dizer..." Esses dias eu mostrei uma pra um cara que disse: "você é poeta? Ou você copia os versos dos outros?", não porque eu tivesse raiva dele... a resposta não a ele, a resposta a... como eu posso dizer àquela atitude que às vezes é coletiva. (trecho da transcrição do $1^{\circ}$ encontro das Conversas Poéticas, 08/06/2013).

Resposta a atitudes coletivas.

Nego Panda também vê desse modo o papel da escrita.

Escrita política. Num contexto coletivo. Resposta às situações de injustiças pelas quais se passa. E entende-se que tantos outros passam também...

Eliane: E usando o exemplo da Ludimar ali da resposta, você já fez pra responder pra alguém?

Nego Panda: Não. Pra responder algo que tivessem feito pra mim que eu me recorde no momento, não, mas já fiz poesias inspirado em outras poesias que eu vi. Tem uma escrita que eu achei legal e falei "tenho que fazer isso também". Agora uma resposta assim de algum momento que eu passei não, a gente acaba fazendo algumas poesias... tipo cê passa por uma situação desconfortável e acaba escrevendo, mas geralmente quando eu vou escrever eu vou escrever eu acabo colocando tudo num contexto coletivo porque se eu passo por uma situação de discriminação, nesse mesmo momento lá na Bahia tem uma pessoa que ta passando pela mesma situação de discriminação, no Paraná, em Rondônia, então acaba sendo um ciclo coletivo porque muita coisa acontece ao mesmo tempo, então eu penso que muita coisa ta acontecendo ao mesmo tempo, penso que o que ta acontecendo aqui ta acontecendo ali. Então eu acabo fazendo um social. (trecho da transcrição do $1^{\circ}$ encontro das Conversas Poéticas, 08/06/2013).

Eliane: Tem algum poema seu que já aconteceu com você? Que você viu e escreveu?

Nego Panda: Poema que já aconteceu comigo? Quando a gente escreve sobre injustiça social, essas coisas e a gente é pobre, basicamente muita coisa já aconteceu com a gente. Quando a gente escreve sobre preconceito por ser pobre, preto, morador da favela, o pessoal já te olha assim com o olhar torto então muita coisa já... não é... você não faz uma autobiografia, mas muitas coisas acabam sendo, meio que acabam caminhando lado a lado. (trecho da transcrição do $1^{o}$ encontro das Conversas Poéticas, 08/06/2013). 
Resposta. Escrita.

Para onde isso me leva?

Escrita individual? Escrita coletiva? Minha voz? Voz do outro? Alteridade?

Língua que é minha. Língua estrangeira?

A resposta de Abel segue ideia semelhante. Mais vivência que invenção.

Eliane: Tem alguma coisa da sua vivência no que você escreve?

Abel: Eu gosto de escrever as coisas pra pessoa ouvir e já entender, pare pra pensar por que será que ele falou assim? O que que ele quis dizer com isso é mais pra fazer pensar $90 \%$ são coisa da minha vivência. Uns $10 \%$ seria fantasia. Eu poderia tirar uma coisa de um filme, mas aí seria os $10 \%$.

A Egos e ambições era uma letra de rap que eu havia feito, coisas que você passa e que você almeja ao mesmo tempo e ao mesmo tempo não é nada disso às vezes conforme uma ambição que você tem.

Fernandes pergunta a ele: Eno mundo você acha que todo mundo ta dosando bem os egos e as ambições, sem se preocupar como vai chegar lá?

Abel: Todo mundo ta querendo um lugar de destaque sem saber. (trecho da transcrição do $3^{\circ}$ encontro das Conversas Poéticas, 23/02/2014).

Mas, posso olhar de outro modo?

E a invenção presente na escrita?

Deleuze vai além da vivência. Para a função fabuladora da escrita.

A saúde como literatura, como escrita, consiste em inventar um povo que falta. Compete à função fabuladora inventar um povo. Não se escreve com as próprias lembranças, a menos que delas se faça a origem ou a destinação coletivas de um povo por vir ainda enterrado em suas traições e renegações. (...) Precisamente, não é um povo chamado a dominar o mundo. É um povo menor, eternamente menor, tomado em um devir-revolucionário. Talvez ele só exista nos átomos do escritor, povo bastardo, inferior, dominado, sempre em devir, sempre inacabado. Bastardo, já não designa um estado de família, mas o processo ou a deriva de raças. Sou um animal, um negro de raça inferior desde a eternidade. É o devir do escritor. Kafka, para a Europa central, e Melville, para a América, apresentam a literatura como a enunciação coletiva de um povo menor, ou de todos os povos menores, que só encontram expressão no escritor e através dele. (DELEUZE, 1997, p. 14).

Devir-revolucionário.

Devir. Invenção.

Descobrir.

Inventar na língua aquilo que se quer dizer.

Fazer dançar.

Nas palavras de Ludimar:

Eu escrevo em qualquer lugar. Às vezes assistindo televisão, às vezes deitada na cama, às vezes na rua, qualquer lugar, qualquer momento eu já vou captando o que eu quero escrever...

Uma vez eu estava fazendo uma faxina, um calor em pleno janeiro e eu vi que o galho da goiabeira do quintal vazio do lado tombava na marquise, eu pulei pela janela e peguei a 
goiaba... aquele gosto... veio a infância, os quintais que eu morava que tinha essas árvores e eu fiz: "faça da vida uma goiabada"...

O que eu me permito inventar. Aí é a parte mais legal. Eu gosto muito de inventar, eu acho muito legal essas pessoas que inventam palavras, tem um amigo meu que inventa umas palavras, ele pega um pouco de solidão com saudade, mistura aquilo, dá uma nova palavra, um neologismo... agora inventar é o que eu mais gosto, na invenção eu posso tanto falar verdade como falar mentira, verdade, sonho, eu invento; se eu quiser inventar que essa sala não é uma sala eu invento, se eu quiser falar que a partir de agora essa sala é um túnel que vai me levar pra algum lugar, eu olho pra uma flor e se eu pensar que um dia não vai ser uma flor, essa é a parte mais gostosa, é você inventar, aí é o ato mesmo da criação. Não quer dizer com isso que você está inventando só o que é irreal, você pode até ter um pouco de realidade, mas é uma realidade inventada, que é a realidade melhor que tem. Aí volta de novo na Pasárgada, do Manoel Bandeira, tão amada por mim. Inventar é a parte mais gostosa.

Faça da vida uma goiabada.

Inventar é o que eu mais gosto.

Essa é a parte mais gostosa.

É o ato mesmo da invenção.

Realidade inventada.

Pasárgada.

Devir do ato criador.

O que dizer, então, sobre escrita vivência / escrita e invenção?

Talvez, o devir-escrita não tenha que fazer sentido, apenas fazer sentir...

Sentir do leitor...

Obra que se mistura ao autor.

Fronteira entre o que se vive e o que se inventa.

Escrevo. E pronto.

Escrevo porque preciso,

Preciso porque estou tonto.

Ninguém tem nada com isso.

Escrevo porque amanhece,

E as estrelas lá do céu

Lembram letras no papel,

Quando o poema me anoitece.

A aranha tece teias.

O peixe beija e morde o que vê.

E eu escrevo apenas.

Tem que ter por quê?

(LEMINSKI, 2002, p. 135).

O que isso potencializa enquanto experiência criadora?

E o que dizer sobre as margens? Elas existem?

Para onde vai a margem do rio quando seca?

E quando o rio transborda? Existe margem?

O que dizer de uma periferia que deixa as bordas da cidade e ocupa o centro da cidade?

Que tamanho tem essa literatura?

Literatura menor? Maior?

Devir-literatura. Literatura que atinge as profundezas da linguagem... 
De que modo os poetas aqui trazidos para a roda torturam, quebram a língua?

Vejo essa "quebra" em alguns poemas que leio nos livros dos poetas.

Ei você me conhece?

Sabe quem sou?

Da onde vim?

Pra onde vou?

Sigo procurando

Essas respostas

Sou atrevida

Entro sem bater na porta

Machuco sem querer

E deixo a vítima

Às vezes morta

Sou forte pequenina

Mas rápida

Qual uma andorinha

Quebro o silêncio

Da noite

Faço sangrar tipo açoite

Derrubo o fraco ou o forte

Exalo o cheiro da morte

Arranco um grito de dor

Te faço ganhar uma flor

Ainda não sabe quem sou?

Eu sou a bala perdida

Que sem avisar ceifa a vida

Levando aquela criança

Que brincava em casa ou na rua

Mas me diz

Se a culpa é minha ou sua?

(NEGO PANDA, Bala perdida. 2011, p. 24).

Vemos que Nego Panda escreve como se fosse um objeto, o qual só revela quem é ao final do poema. Ao fazer isso, leva o leitor a se colocar numa posição de curiosidade. A pergunta ao final “A culpa é minha ou sua?" o coloca numa posição de quem questiona. De quem é a culpa?

Seria a esse "quebrar" a língua que Deleuze e Guattari se referem quando buscam caracterizar a literatura menor?

Servir-se do polilinguismo em sua própria língua, fazer desta um uso menor ou intensivo, opor o caráter oprimido dessa língua a seu caráter opressor, encontrar os pontos de não-cultura e de subdesenvolvimento, as zonas linguísticas do terceiro mundo por onde uma língua escapa, um animal se introduz, um agenciamento se ramifica. (DELEUZE; GUATTARI, 2003, p. 41-42).

Por onde a língua escapa?

o bicho alfabeto

tem vinte e três patas

ou quase 


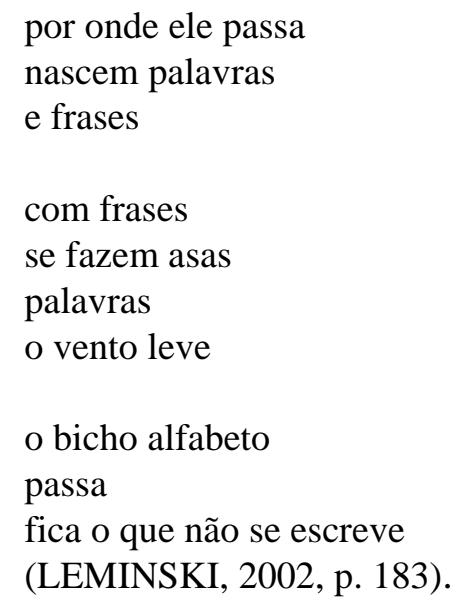

Que o "bicho alfabeto" continue instigando pensamentos, em forma de asas leves, na escrita do Sarau das Ostras e de tantos poetas pelo Brasil e pelo mundo afora.

Escritas que se querem políticas, coletivas, desterritorializadas.

Literatura menor? Poemas marginais? Quem sabe...

Pensamentos que não cabem.

Movimentos de ler, escrever e compartilhar poesia que seguem em direção ao infinito.

A escrita... um movimento de atravessar fronteira. Como colocar em palavras tanto saber e tantas emoções que perpassam o ato de encontrar, compartilhar, ouvir, ser contagiada, sentirme impactada? Esse foi, durante um período de quatro anos, o meu barato. Barato de inventar um modo de escrever poeticamente um texto de pesquisa.

Movimento baratinado... baratinante... desbaratado... ser educadora, pesquisadora, autora.

\section{Referências}

BACOCINA, E. A. Ler, escrever e compartilhar poesia: práticas (DES) territorializadas, políticas, coletivas. Tese (Doutorado). Universidade Estadual Paulista / UNESP, Rio Claro, 2017.

DELEUZE, Gilles. Crítica e clínica. São Paulo: Editora 34, 1997.

DELEUZE, G.; GUATTARI, F. Kafka: para uma literatura menor. Lisboa: Assírio e Alvim, 2003.

FERNANDES OLIVEIRA. Minhas pegadas na areia. Praia Grande/SP: Literata, 2011.

LEMINSKI, P. 1944-1989. Melhores poemas de Paulo Leminski. GÓES, Fred; MARINS, Álvaro (Org.). 6. ed. São Paulo: Global, 2002.

MOLINA, L. G. Ludicidade. Praia Grande/SP: Literata, 2011.

NEGO PANDA (NP). Poesias de um mundo louco. Praia Grande/SP: Literata, 2011.

RO3P. O sonho dus guerreiros não morre! CD. KiHap Produções: Praia Grande, 2013.

ROLNIK, S. Cartografia sentimental: transformações contemporâneas do desejo. Porto Alegre: Sulina; Editora da UFRGS, 2011. 